\title{
Promoting Pedagogical Agility in Learning Spaces: Toward a Comprehensive Framework of Faculty Support and Innovation
}

\author{
Crystal M Ramsay \\ The Pennsylvania State University \\ cmg5@psu.edu \\ Jenay Robert \\ The Pennsylvania State University \\ jirr296@psu.edu \\ Jennifer Sparrow \\ The Pennsylvania State University \\ j1s997@,psu.edu
}

\begin{abstract}
Postsecondary instructors routinely face novel and complex challenges in physical classrooms and informal learning spaces. Instructors often bring these challenges, along with creative and aspirational solutions, to the attention of centers for teaching and learning (CFTLs). Issues span a wide range of topics including blogs, clickers, immersive experiences, active learning, learning analytics, and more. At Penn State, we embrace these challenges and seek to cocreate solutions by providing a wide net of resources and support characterized by (a) instructional technologies, (b) instructional design, (c) faculty development, and (d) research. These elements emerge as a generalizable framework that represents a dynamic research-to-practice cycle. The cycle begins with a combination of problem definition and existing research. An approach is then planned and executed according to the framework. In accord with the cyclical nature of the framework, research findings inform development of future instructional design and faculty development opportunities. These, in turn, inform future practice, and the cycle continues. In our CFTL an educational research team collaborates with an instructional design and development team to support and facilitate this research-to-practice cycle. We illustrate the practical implementation of this recursive and generalizable framework as we report on a case study of one technology-enhanced experimental classroom space. We conclude with a discussion of how the framework might inform larger efforts to integrate research with instructional technology implementation, instructional design, and faculty development.
\end{abstract}

Keywords: learning spaces, instructional design, faculty development, research.

Like many of our peer institutions, Penn State has worked across the university to provide a stellar educational experience for all students. As the university seeks to create the most impactful learning experiences possible, it leverages existing and original research to inform practice. This informed approach to educational innovations has allowed the university to adopt and adapt practices that are intended to increase student success. One area in which this research-to-practice cycle has been adopted is in technology-enhanced learning spaces.

A learning space is simply a space where learning can happen. Broadly speaking, this could be just about anywhere; a car, a diner, and the forest can be learning spaces. Learning that occurs in such spaces may, or may not, be intentional. In higher education, in contrast, learning spaces are typically those in which learning is intended to happen. These may be formal or informal spaces; they may be physical or virtual. Regardless, learning spaces are getting more attention, largely because there is 
increased recognition that the learning environment is a critical variable in the learning process (e.g., Graetz, 2006).

It is sometimes overlooked that transforming education requires the transformation of the student learning experience. This can be achieved through the strategic use of digital tools and applications, explanatory and predictive data strategies, and new instructional technologies. At Penn State, decisions to implement potentially transformative tools and approaches are grounded in existing research and further explored through original research. Physical learning spaces can serve as incubators for the implementation and experimentation of new tools geared toward student-centered pedagogies.

\section{The Challenge and Proposed Solution}

Faculty need tools and strategies to help solve their instructional challenges and also to inspire their thinking about pedagogical innovations. They also need to feel supported in their own experimentation. At Penn State, the vision is that faculty - regardless of the content they teach, where they teach it, or the modality by which they engage with students-will be sufficiently agile to make optimal pedagogical decisions for their context. To realize this vision, three factors are foundational: space, support, and process. Previously at our institution we had no space designated for systematic exploration and experimentation. Moreover, we lacked a robust system for supporting faculty around the implications and opportunities of technology-enhanced learning spaces. Finally, we needed a process, grounded in research, to drive exploration and innovation.

To address this challenge, Penn State's center for teaching and learning (CFTL), Teaching and Learning with Technology, proposed and deployed a multifaceted approach: (a) Create a space that is equipped with instructional technologies and intentionally designed for pedagogical experimentation, (b) leverage best practices in instructional design and faculty development to provide a unique and far-reaching model of support, and (c) engage in an ongoing research-to-practice cycle to support faculty in their own scholarship of teaching explorations and to inform creation of reproducible models as we scale spaces across our institution. In this article, we begin with an elaborated description of this multi-pronged approach, follow with a report of a longitudinal exploratory case study of its application to a particular space, and conclude with an emergent framework of faculty support.

\section{Create a Technology-Enhanced Space Designed for Experimentation}

Instructional technology. The Oxford Dictionary defines technology as "the application of scientific knowledge for practical purposes, especially in industry." Our operational definition of instructional technology is similarly far-reaching and relevant to pedagogy: the application of functional tools and space to enhance the teaching and learning experience and to promote instructional goals. In our learning spaces, we consider furniture, digital displays, writable surfaces, power sources and outlets, and the flexible space itself to be instructional technologies. Importantly, our perspective is that no instructional technology is inherently valuable. Rather, it becomes valuable and desirable to the extent that it can support faculty and students in solving challenges and exploring and pursuing novel ideas. It is, therefore, our practice to provide faculty with the newest and most innovative tools. It is in intentionally experimental spaces that the viability and efficacy of these tools can then be tested. When instructional technologies are deemed to be valuable, they can then be strategically proliferated across the institution for wider use.

The Bluebox. The room selected for renovation was the only academic classroom in one of our university's science buildings. At 1,263 square feet, its capacity was 100 students (Figure 1). Seats were front facing and fixed to the floor. There was a chalkboard at the front and an area designated as a 
stage by carpeted flooring and a cable for instructors to plug in a computer. A projector in the ceiling allowed instructors to project content onto two side-by-side screens at the front.

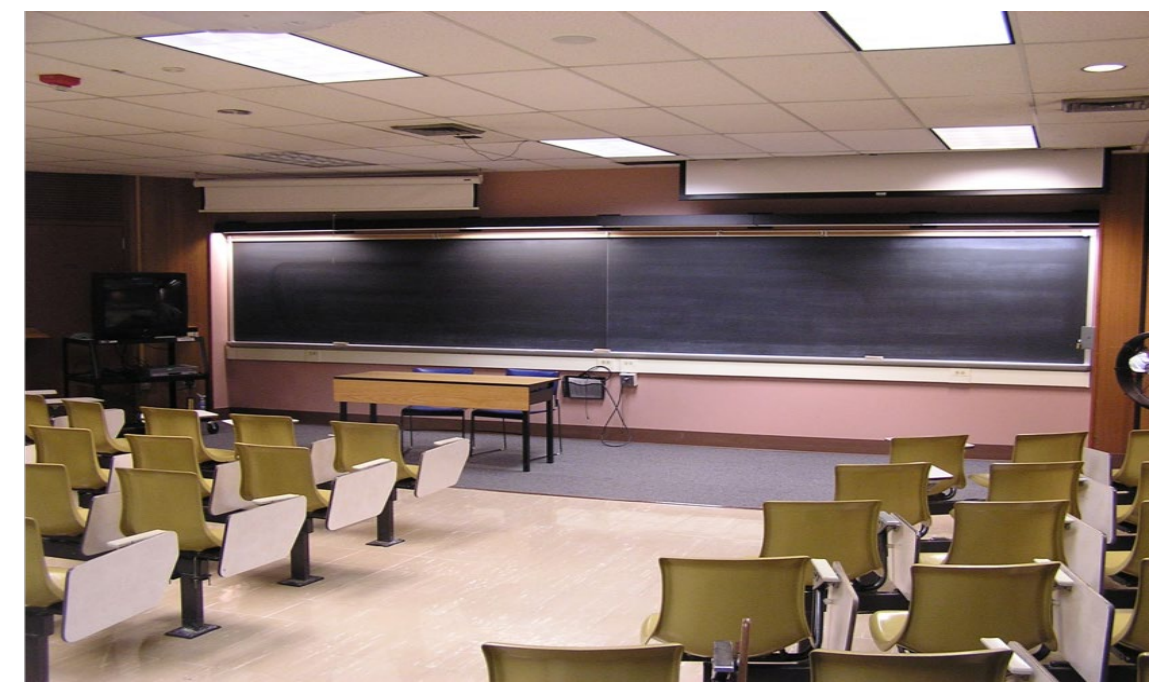

Figure 1. Classroom before renovation.

In its new incarnation, the classroom now designated the Bluebox is the same square footage, but its capacity is now 44 students (Figure 2). Variable-height tables and chairs allow for unobstructed sight lines to anywhere in the room without having to tier the floor. Furniture is also mobile so the room can be reconfigured to support collaborative and interactive instructional activities. The Bluebox also boasts a variety of writable surfaces: writable walls, magnetic whiteboards, and mobile whiteboards that can also serve as partitions if desired. The projector was replaced with wireless content-sharing capabilities for both faculty and students. A large, touch-enabled digital display replaced the screens and allows for the simultaneous sharing of both static and dynamic content. Electrical outlets and USB ports along the perimeter of the room, as well as power in the floor, provide abundant and anytime access. An adjustable metal structure was installed in the ceiling to facilitate the quick installation of new technology as it is desired for experimentation.



Figure 2. Classroom after renovation. 


\section{Provide a Unique Model of Support for Faculty}

The ubiquity and importance of technology in higher education (e.g., Becker et al., 2017) requires an accompanying vigilance to understand and promote its effective use. This is especially true to the extent technology can promote or impede learning (e.g., Clunie, Morris, Joynes, \& Pickering, 2018; Ross, Morrison, \& Lowther, 2010). Therefore, merely equipping classrooms with instructional technologies is insufficient if the expectation is appropriate and successful faculty adoption and implementation. Two decades ago, Rogers (2000) argued that successful technology integration requires accompanying faculty development that is experience based, immersive, and further characterized by the inspiration for invention and responsiveness to the curiosities, concerns, and perspectives of the faculty (McKenzie, 1991, as cited in Rogers, 2000, Table 2, p. 23).

We built upon early models of support for instructors who teach in technology-enhanced active-learning classrooms such as that provided at the University of Iowa for faculty teaching in TILE (Transform, Interact, Learn, Engage) classrooms (Van Horne, Murniati, Gaffney, \& Jesse, 2012) and at Indiana University where the Mosaic Active Learning Initiative supports faculty, regardless of discipline, with a "comprehensive set of services and strategies" ("IU creates Mosaic initiative," 2015). Our own model for collaborative work with faculty seamlessly integrates elements of both instructional design and faculty development in such a way that it is often impossible to determine where one ends and another begins.

Incorporating instructional design. Leveraging singular tools for narrow purposes is inefficient and results in missed opportunities for creative learning experiences for students. We endeavor to support faculty in becoming savvy and creative users of the best instructional technologies available. Supporting faculty in becoming pedagogically agile requires provision of job-embedded and ongoing opportunities for experimentation and feedback. We addressed this by combining the best attributes of instructional design with faculty development programming.

Instructional designers partner with faculty in experimental learning spaces to explore novel course design possibilities and the implications of the physical space for those designs. This may entail course redesign, implementation of new instructional strategies, or larger scale experimentation with hybrid instruction that bridges both the experimental physical space and an online space. Instructional design support may occur one-on-one or at a group level.

Despite current ambiguity about the specific role of instructional design in higher education (Beirne \& Romanoski, 2018; Intentional Futures, 2016), the role of instructional design in our proposed support model is clear: Instructional design skills are leveraged to support faculty in whatever ways their instructional challenges require. Instructional design partnerships are indeed partnerships. Instructional designers do not seek to create pedagogical products for our faculty partners but rather to cocreate and learn with them. In all of our efforts we strive to support pedagogical agility. As Beach, Sorcinelli, Austin, and Rivard (2016) have noted, "Faculty development is everyone's work" (p. 7). As such, we consider instructional designers to be central to our wideranging system of support. Thus, we often find it difficult to distinguish instructional design from faculty development.

In their recently updated study of the higher education faculty development landscape, Beach et al. (2016) reported the top approaches that faculty developers agree are essential to support faculty. These include faculty learning communities, asynchronous web-based resources, and peer observations of teaching with feedback (Beach et al., 2016). Recognizing these approaches, we designed the following set of faculty development experiences for Bluebox faculty.

- A tech tour: Faculty participated in the tech tour prior to teaching in the Bluebox for the first time. Part 1 of the tour was a basic technical tutorial for using the less intuitive instructional 
technology (e.g., large touch-enabled display wall). Participants left the tech tour with an assignment: Come back in a week with sample content and ideas about how to leverage this space and its affordances. A week later, the faculty cohort reconvened to share their ideas about how they planned to use the space, and they actually practiced in a modified microteaching session.

- A faculty-facing website: We created a website just for faculty teaching in the Bluebox. It included such information as syllabus language relevant to the space and its tools; a first-day-of-class assignment to help familiarize students with Solstice, the wireless content-sharing platform; calendar of classes and instructors scheduled in the room; and resources about active learning.

- A schedule of check-in meetings: Regular check-in meetings of the faculty cohort were designed as an open forum for discussing logistical and instructional successes and challenges.

\section{Engage in an Ongoing Cycle of Research to Practice}

Existing research. When faculty first share their instructional challenges and aspirations with a CFTL, the search for solutions begins by exploring and leveraging existing research. Inherent in this part of the cycle is a diagnostic assessment of the true challenge. As the problem definition is clarified, CFTLs are well positioned to translate existing research and to collaborate with faculty to imagine novel and useful applications of it to address the challenge. Sometimes this is a solution to address a unique challenge experienced by one instructor. For example, how can an instructor in a large chemistry class use technology to provide more accessible office hour opportunities for students and an overall more efficient approach for the instructor? At other times, groups of faculty face a common challenge. For example, formal and informal faculty learning communities are curious about ways to use active learning techniques in both traditional and technology-enhanced flexible learning spaces. Regardless, with existing research as a foundation, a holistic approach is crafted that includes a combination of the following: appropriate instructional technologies, instructional design and faculty development, and original research.

Original research. Research is, by definition, intentional and systematic. Learning spaces require two types of research exploration: stakeholder research and scholarly research. In the context of learning spaces, at Penn State we define stakeholder research as the systematic investigation of questions that are of interest to our institution's Office of the Physical Plant, institutional committees on physical spaces, the university registrar, and others whose interests reflect the infrastructure, financial investments, and overarching operations of the university. We use common approaches to address stakeholder questions such as administration of pre- and post-occupancy surveys, distribution of questionnaires, and engagement of focus groups. The primary foci of these types of data sources are satisfaction and efficiency. Still, findings are important, as they inform designs of future spaces.

In contrast, we define scholarly research in learning spaces as the systematic investigation of questions about pedagogy, learning, and the teacher and student experience. To address our scholarly questions, we use common instruments such as interviews and focus groups. In addition, we have created multiple new methods of collecting data to better address our scholarly research questions. These are described in detail in the case study below.

Once new learning emerges from original research, we recast it as existing research. It becomes actionable and informs pedagogical practice or space design, and the cycle begins again. Importantly, the separate components of the support model described above do not necessarily occur linearly or independently. Instead, they occur pragmatically, and often concurrently. The case study below exemplifies the process. 


\section{Methodology: A Case Study}

Since the inception of the Bluebox in fall 2016, our research team has engaged in multiple projects examining the relationship between the Bluebox space (i.e., the space itself, its flexible furniture and tools, and its instructional technology) and the teaching and learning that take place there. Over time, we have accumulated data from multiple sources, including interviews and focus groups with faculty and students, photographs, documents, classroom observation tools, experience sampling, and video and audio recording. Taken together over the course of five semesters, these data have allowed us to curate a longitudinal exploratory case study (Hartley, 2004) of the Bluebox space.

Interviews. Five faculty members and one student representing four content areas engaged in one-on-one interviews in the fall of 2017 and 2018. Interviews ranged in length from 20 to 90 min. The structure of the interviews varied by semester. For fall 2017, interviews were semistructured and focused primarily on follow-ups on the Re-Capture meetings described below. For fall 2018, interviews were open-ended and prompted participants to reflect on their holistic experiences in the Bluebox over time. All interviews were transcribed verbatim, and selected quotes were lightly edited for readability.

Focus groups. Across four semesters, fall 2016, spring 2017, fall 2017, and fall 2018, Bluebox students were invited to six focus-group sessions. Questions at these sessions focused on the student experience, including engagement and impact of the space on learning.

Flashbacks. Flashbacks, a form of experience sampling, were weekly prompts that targeted faculty planning and experiences in the Bluebox (Ramsay, Guo, \& Pursel, 2017). We designed them as a frequent yet unobtrusive means to encourage faculty engagement in reflective practice. Faculty responded to the prompts via text or video. A total of 272 responses from 24 faculty members were collected over three semesters, fall 2016, spring 2017, fall 2017. Selected quotes were lightly edited for grammatical correctness and readability.

Re-Captures. Faculty accessed a digital space within the Google Drawing interface to reflect on physical classroom configurations afforded by the Bluebox that helped them meet instructional goals in ways that traditional classrooms could not (Ramsay, et al., 2017). Reflection prompts were embedded within a dynamic visual representation of the Bluebox. This representation included tables, chairs, and mobile whiteboards that could be manipulated using drag and drop functionality. Once in the interface, faculty "re-captured" physical configurations of the Bluebox in response to the prompt and elaborated in a provided text space on its impact. Over three semesters, fall 2016, spring 2017, fall 2017, 19 faculty members shared 19 different configurations of the space and described the difference the configurations made to their teaching. Structured cohort check-in meetings allowed for interactive and cross-disciplinary discussions of these configurations.

$V$ ideo and audio. Over two semesters, spring and fall 2018, our research team developed a novel $360^{\circ}$ video methodology (Robert \& Bekiroglu, 2019) to capture the dynamic environment of the Bluebox. We strategically placed a $360^{\circ}$ camera and four microphones around the Bluebox to capture a $360^{\circ}$ perspective of activity taking place. The video was later analyzed for, and with, faculty. Whereas traditional video methods force a researcher to focus on predetermined areas of interest, $360^{\circ}$ technology has allowed our team to observe the Bluebox as a holistic active-learning environment. Three classes participated in this portion of data collection with a total of 13 class sessions being recorded. Segments of these recordings were used as prompts for an interview with one faculty member as well as an interview and a focus group with her students. 


\section{Data and Results}

Reviewing our corpus of data has led to an understanding that the Bluebox is the epicenter of the overarching framework we have observed emerging in our CFTL. That is, our data indicate that the story of the Bluebox is an outstanding exemplar of educational research, instructional design and faculty development, and instructional technology, all working in tandem to support our faculty and students. By design, the Bluebox has been a site for both scholarly and stakeholder educational research. This case study is itself evidence of the experimental nature of the space. Our team has used the room and our collaborative relationships with the faculty who teach there to develop novel methods: Flashbacks, Re-Captures, $360^{\circ}$ video, and more. Data from these, as well as more traditional methods, have informed a robust research agenda in the space and also helped inform faculty members' thinking about teaching and learning, thus contributing to the research-to-practice cycle described previously.

\section{Instructional Design and Faculty Development}

In addition to the programmatic instructional design and faculty development support provided to Bluebox faculty, their interaction with each other and with the space itself serves as informal instructional design and faculty development support as well. When asked about pursuing more formal modes of support, some faculty who teach in the Bluebox have reported that they are independently thinking about innovative ways to teach their classes, and many of them have participated in extensive programming in the past. For example, in a one-on-one interview [fall, 2018], Darin ${ }^{1}$ explained:

I come into this having spent years working with collaborators in science education.... Plus I also design and teach a bunch of courses online, so I worked with the learning designers going back years. So I guess I had pretty well developed ideas of what I wanted to do before I even got into this space. It was more like, I'm not looking for a ton of new ideas, I'm just looking for a place to implement them.

Bluebox faculty have found that meeting with our education research team and also meeting with each other through research activities have served as a mode of faculty development. In a oneon-one interview [fall, 2018], Trent talked about his relationship with one of the researchers and his engagement in various research activities:

[The researcher] catalyzed a lot of our thinking about how to use the space. In particular, the first two semesters we were in there, she had meetings of all of the different people who were teaching in there together. And this is something I have to say I was very skeptical of from the beginning. But I learned something at every one of those [meetings].

During Re-Capture discussions, faculty reported on the utility of room configurations that were presented by their colleagues. For example, Emerson commented on a particular configuration: "Though we did not use it this semester, it is a style of activity I would love to try in future classes" [spring, 2017]. For another configuration, Graham said: "I never tried anything like this, but I find it interesting" [spring, 2017]. In this way, faculty who teach in the Bluebox have begun to form an

1 All participant names are pseudonyms. 
informal community of practice, inspiring each other's thinking about the use of the space for innovative and often research-based pedagogical approaches.

In addition to being inspired by each other, the faculty who teach in the Bluebox are inspired by the space itself. Typically, faculty find themselves reflecting on their current use of the space and wondering how they can experiment with the features of the room to make their classes more engaging. We saw significant evidence of this phenomenon in Flashback data. Brent described a situation in which he found the room in an unusual configuration and decided to try it for that day's activities [fall, 2016]:

We tried it out and it went well. Large group conversation went well in that arrangement and we didn't have our usual small group activity for the last class so it may have been even better than the usual set up for this week.

Faculty also reported that they found inspiration in the interactive digital display in the room (Figure 3). Kristine wrote, "I'm planning to try a bit more with the display in the coming weeks" [fall, 2016]. Brent was interested in incorporating the display to promote sharing work done in small groups in larger group discussions [fall, 2016]:

So maybe I have to rethink if there's aspects of the Solstice application that I'm not taking advantage of there.... I need to rethink the incentive for students to use the whiteboard and to use the Solstice display, because it seems right now, they're happy to just work within their [small] group and not share [with] the large group.

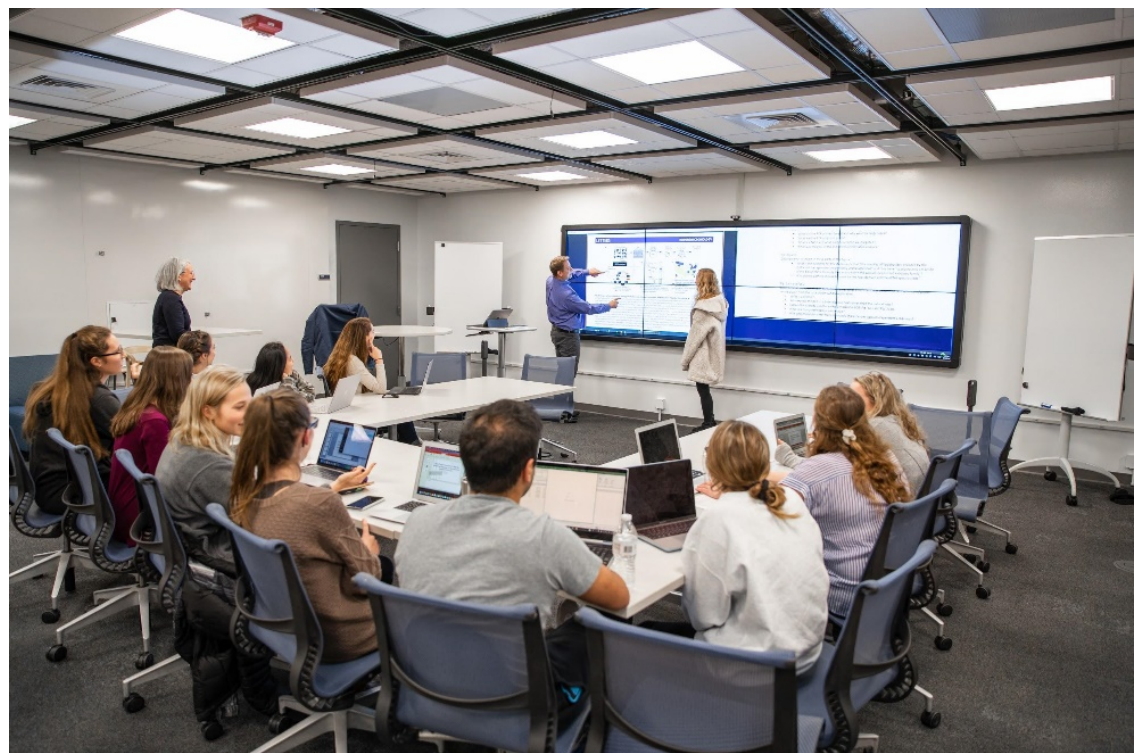

Figure 3. Demonstration at the display. Faculty and students concurrently share digital content.

Even beyond being motivated to change her pedagogy in the classroom, one faculty member reported that the writable surfaces in the Bluebox "made us think about how writing on the walls could be something to explore in our counseling rooms in [another building]" [Jadelyn, spring, 2017]. Finally, faculty reported that these reflective practices-being inspired by their colleagues' use of the space and by the space itself-led to tangible improvements in classroom practice. For example, Garvin reported: 
As the semester moves along, integration of the various Bluebox affordances is becoming more second nature to us as instructors and as a by-product, class has become a much more active, participatory experience. A lot less time in class is devoted towards traditional lecture. Though we did not set about to "flip" the classroom, the room lends itself to more active approaches to teaching and it is equal parts energizing and effective to take advantage of it. [spring, 2017]

Because our Flashback data indicated that faculty often gained inspiration from the space and their colleagues to modify their pedagogy, we directly asked them about instructional changes in the following Flashback prompt [spring, 2017]: "Do you plan to revise and/or add a learning activity based on your most recent experience in this space? If so, what? Why?" Multiple faculty indicated that they did indeed plan to modify their curriculum to incorporate more features of the space:

I would like to add in an activity that involves group work, to experiment with how the moveable furniture works.... I also have not [used] the Solstice app very much with students beyond the first-day mapping activity, so I would like to use this more across the semester but haven't yet decided on a way to do so. [Graham]

As the semester progresses, using the whiteboard for small group brainstorming followed by sharing and class discussion is becoming a bigger and bigger part of the in-class experience. I know I've mentioned it in previous responses, but having the students take advantage of the whiteboard space to demonstrate their knowledge has proven to be a far more effective (and richer) educational experience than simply lecturing for 50 minutes. The more we engage in these sorts of activities, the harder I find it to imagine teaching without them. We have some upcoming team-building and prototyping activities that I would expect will be reconsidered with the whiteboard space in mind, and some traditionally lecture-based content that I think we will revise to take better advantage of the space.... We've also enjoyed our experience using Solstice to encourage student media sharing and would like to continue to integrate that into the course moving forward. [Garvin]

Currently we do several case studies but I would like to expand the case studies to include having the groups present their findings to the rest of the class by using the white boards and writable wall space. [Jocelyn]

I want to revise my tutorials so they more strongly encourage students to work things out on the whiteboard space. [Terri]

Faculty tend to come to the Bluebox because they are already self-reflective practitioners who own their own instructional design. Thus, the flexible space serves as a creative canvas that inspires their thinking and facilitates their goals. Furthermore, engagement in our CFTL's research activities allows Bluebox faculty to connect with each other, generating further opportunities for informal instructional design and faculty development.

\section{Instructional Technology}

The instructional technology in the Bluebox helps faculty engage students in learning activities and meet their pedagogical goals. Faculty who teach in the Bluebox have consistently reported that one of 
their pedagogical goals is to increase student engagement. In an interview [fall, 2018], Trent explained that he and his colleague had been displeased with traditional teaching spaces because it was difficult to get students engaged: "It was hard to make groups among students and have them talk to each other." Even as a self-described lecturer, Darin described the types of interactions he was seeking from his students:

I have lots of short discussion questions, give them a minute to think-pair-share-not like a voting-style question but a share-out discussion-style question. Then we construct a lot of information together where I will pose a question and leave it up on the screen and then give them time to talk and then we'll, back and forth between us, we'll sort of construct some ideas. Then occasionally I have them do things where it's more structured: Talk in your group, come up with an idea, sketch it out and then everybody share with each other. [Interview, fall, 2018]

Specifically, our data support two conclusions: (a) Access to flexible furniture and digital tools supports student engagement, and (b) students make use of vertical writing spaces to make their thinking visible to each other and to their instructors.

Flexible furniture and digital tools. The overall flexibility of the Bluebox classroom created new opportunities for faculty and student interactions (Figure 4). Like most Bluebox faculty, Darin asserted that the furniture and tools in the room helped facilitate student engagement. In a Flashback, he shared that a visitor to his class shared his opinion:

One thing that I noticed this week, basically because I had a visitor to my class who sat in and gave me some feedback, and he pointed out that the one thing about the furniture is it makes the students really feel at home. And so he said he felt that that really added to how comfortable they felt in participating in discussions and sharing their thoughts. And so that wasn't something that I would have noticed or considered myself, but he thought it was really something that stood out to him. [fall, 2016]



Figure 4. Multiple opportunities for faculty and student interaction. Each group is able to find a space in the room that meets its unique learning needs and to engage accordingly. 
Multiple faculty reported similar experiences via Flashback responses:

Today, the new furniture was much appreciated. I think students were glad to have some different options to sit around the room. The class environment was helpful as we transitioned between large group discussion and small group discussion several times. [Brent, fall, 2016]

In addition to the seating flexibility of the room which greatly facilitates our ethics discussions, the graduate students have made significant use of the screen for their videos and PowerPoint presentations. I am working on getting them to incorporate more screen interactions from the "audience," although the verbal exchanges we have already had have really been effective. [Kai, fall, 2016]

This week I had students discuss a topic in small groups, and the moveable furniture helped to facilitate these conversations. I then had students report their findings on the marker boards around the room.... I found that the groups seemed to converse longer about the topics and presented more detailed findings than other times where I have just had students present their findings orally without writing them on the board. [Graham, spring, 2017]

The fact that the students can move around AND write on the walls has helped them to be more active participants in the class. When we sat in a traditional classroom, it was difficult to engage many of the students in the middle of the classroom. They tended to lose interest or become distracted. The number of questions and comments and the quality is higher now. [Helena, fall, 2017]

Vertical writing spaces. Faculty have overwhelmingly reported that the vertical writing spaces in the Bluebox support pedagogical goals such as increasing student engagement and learning (Figures 5 and 6). In an interview [fall, 2018], Helena provided a detailed description of an activity that she did with her students in both traditional classrooms and the Bluebox. In short, the activity involved pairs of nutrition students practicing a nutrition counseling session with each other. In a traditional classroom, students would sit in fixed seating and take notes on paper. Helena explained that there were two challenges to this setup. First, it was difficult for her to interact with her students to support their learning:

In a traditional classroom there is no way for me to see what they're writing from far away.... I'd have to ask them to hand it to me. I'd have to really intervene in the flow in what they were doing.... I felt more intrusive.

Second, she knew that students who were clustered in the center of the classroom and not easily accessible to instructional support were quickly disengaging from the activity:

There was a large swath of the group, no matter how the classroom is set up in a traditional classroom, all of those middle students.... They were talking about the weather. They weren't doing an assignment.

In the Bluebox, video and audio data [fall, 2018] revealed that students were positioned at the whiteboard walls to take notes for this activity. Their learning and engagement were supported in two 
ways. First, Helena was able to visit every pair of students and talk to them about their work, supporting their learning and keeping them on task. Second, when students had trouble with the assignment, they were able to look at other groups' work on the vertical surfaces. This would provide them with the information they needed to continue the activity, staying engaged longer than they would have in a traditional classroom space. In an interview [fall, 2018], Olga, a student in Helena's class, confirmed that the vertical writing spaces supported her engagement with Helena as well as with her peers more than a traditional classroom would:

I've never ever been in a classroom that we could all just actually interact with each other and then do a task like that.... The whole design of the room makes for the ability to have more interaction.... [Helena] was able to walk around and be like, "Did you get everything there?” ... She could observe everything and then we could interact with each other.

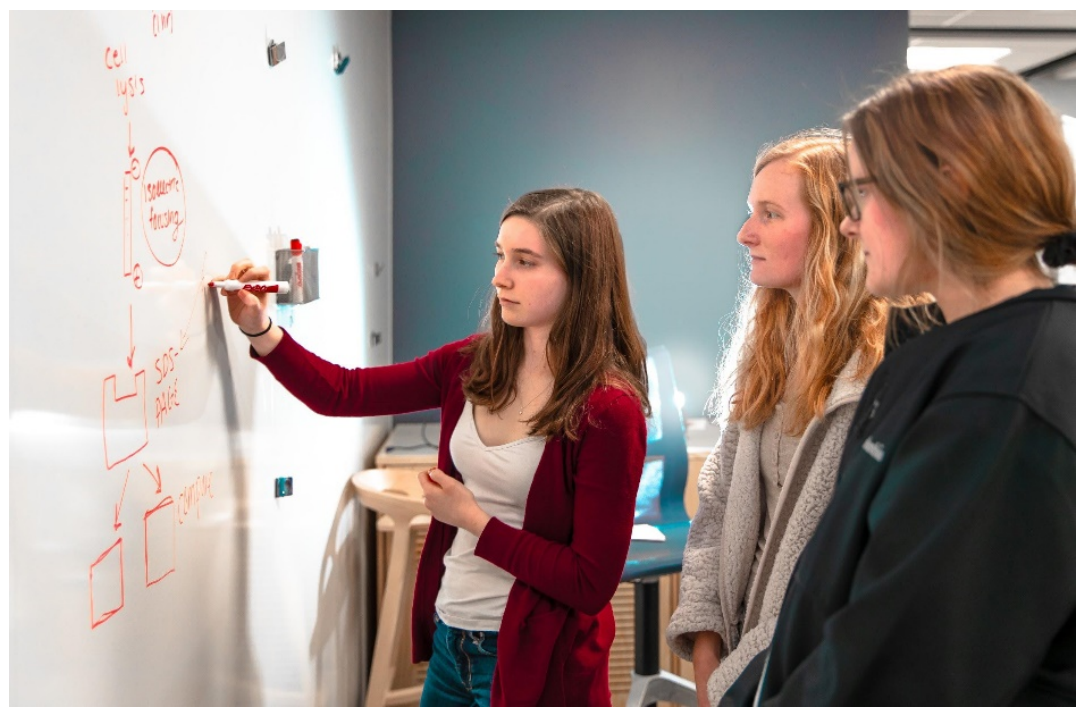

Figure 5. Writable magnetic walls. Students sketch a complex process together.

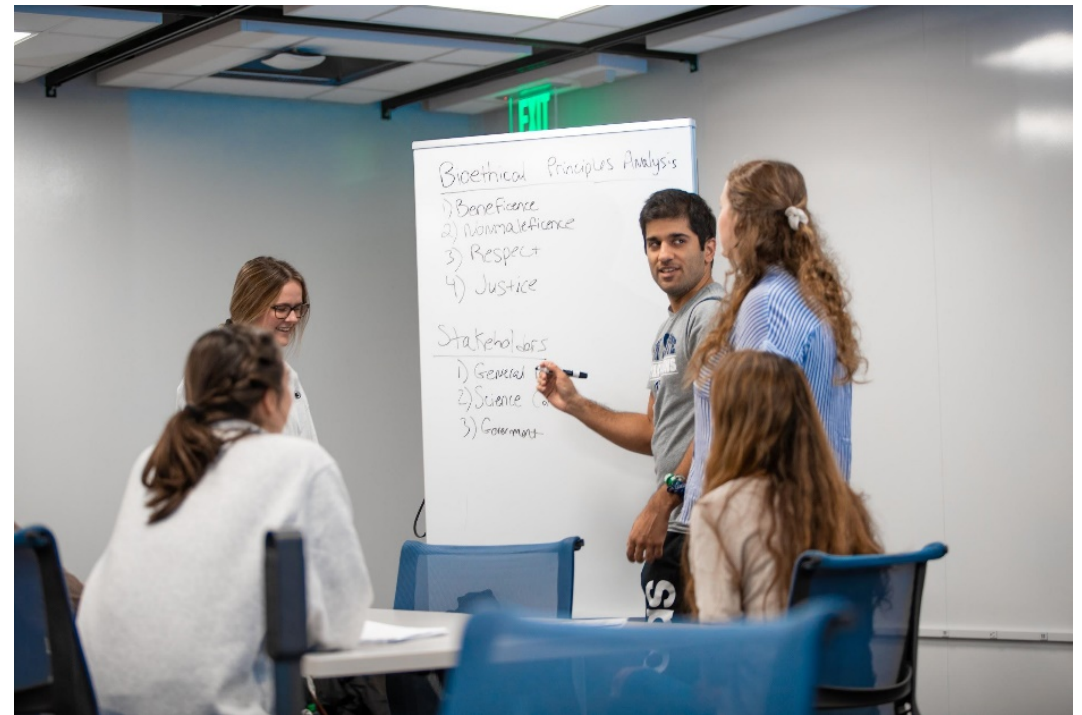

Figure 6. Mobile whiteboards. Students collaboratively brainstorm and then share their work with the rest of the class. 
Olga also confirmed our observation that students were looking at each other's work on the vertical spaces in an effort to move past difficulties with the exercise:

Sometimes if we were stuck we'd look around the room like, "What the heck are other people saying?" ... You would see really great-like so many people had really different, creative ideas, and they were all good.... It helped me to be able to see those as well. Once you see something, you can incorporate that into your learning style.... I think it helped my ability to see things.

Other faculty members reported similar use of the whiteboards in their Flashback responses: We have short discussions where the students are encouraged to share out their thoughts, and we made extensive use of the white boards for this activity again. This simple measure really allows the students to share their ideas in an easy way with each other and to compare and contrast their answers. [Darin, fall, 2016]

Each group of students could use the movable white boards to brainstorm their questions and potential solutions. Students were given sources for these topics that were available online, and they synthesized their responses based upon those [resources] coupled with in class discussions. [Jaime, fall, 2017]

The flexible furniture, digital tools, and vertical writing spaces of the Bluebox have all facilitated the goals faculty have to engage students more deeply in their classes and improve their learning. Faculty are often surprised at how something as simple as a movable whiteboard can act as a powerful engagement tool in the classroom. In this way, our research helps uncover unexpected solutions, both large and small.

Over five semesters, faculty from across disciplines moved their courses from traditional classroom spaces to the Bluebox, a technology-enhanced experimental classroom. They engaged in faculty development activities, both formal and informal, with one another and with our research and instructional design and development teams. The new insights they gained and the new instructional strategies they applied informed our research and their future practice. This overarching approach to supporting faculty compelled us to consider how to better formalize the process as a framework for comprehensive faculty support and innovation.

\section{Emergence of a Framework}

The three-part plan described above was designed to better support faculty in becoming pedagogically agile in any learning space. The Bluebox classroom served as an experimental test space and the faculty who taught in it received the net of support we described. As we documented this process in the Bluebox longitudinal case study, a framework for supporting faculty and promoting pedagogical agility emerged (Figure 7).

The process begins with instructors. They face challenges in their assigned learning spaces. Some challenges can be resolved by applying existing research, strategies, and tools. Others require creative and innovative thinking, new research methods, and a commitment to wide-ranging and ongoing support. It is our practice to make faculty challenges and aspirations our own challenges and aspirations. In support, we cast a wide net of resources: what we know from existing research, appropriate instructional technologies, a combination of instruction design and faculty development skills, programming, and opportunities, and then systematic research to understand the implications. It is not a process that ends; rather, it is a research-to-practice cycle that repeats, each time resulting 
in new learning and improved experiences. As solutions are discovered and applied, new challenges emerge and the cycle is set in motion again. The cyclical nature of the process is evident in the ongoing experiences and exchanges we have had with many Bluebox faculty.

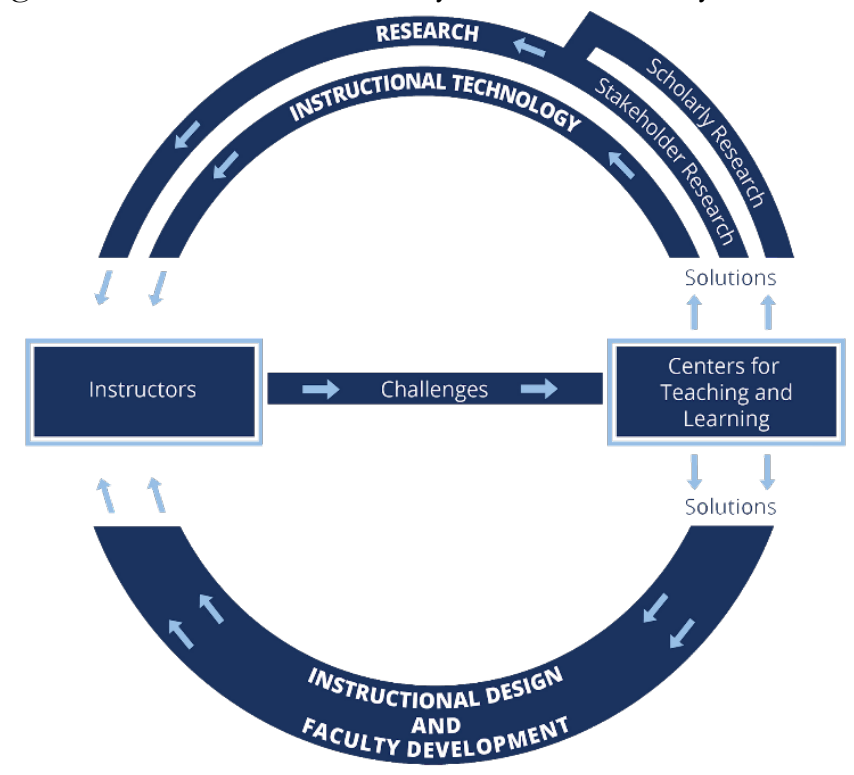

Figure 7. Framework for supporting pedagogical agility. Research, instructional technologies, and a combination of instructional design and faculty development work cyclically and in tandem to support faculty in meeting pedagogical challenges and aspirations for innovation.

\section{Conclusions and Future Directions}

We have reported on Penn State's Bluebox learning space and the application of a new framework to challenges related to physical learning spaces. The reasons for the framework's effectiveness, however, are not unique to learning spaces. Faculty were able to imagine and explore new pedagogies over time and in their own environment. The spaces and experiences designed for them were experimental yet authentic (Haras, 2018). Faculty development activities were both job embedded and ongoing (e.g., Caffarella \& Zinn, 1999). The framework provided faculty support beyond typical one-time workshops (Henderson \& Dancy, 2008; Yoon, Duncan, Lee, Scarloss, \& Shapley, 2007) and supported implementation of new instructional technologies that were aligned both with evidence-based and student-centered pedagogies as well as with trends across the higher education landscape (Diaz, Garrett, Moore, \& Schwartz, 2009). These important attributes of effective faculty support models are characteristic of what is possible given the framework we propose. From this perspective, we believe this framework might be sufficiently generalizable to address other kinds of challenges faculty encounter (e.g., related open educational resources, learning analytics, blended learning) in ways that integrate research with instructional technology implementation, instructional design, and faculty development.

Learning spaces have a role to play in transforming higher education. When we design spaces that are intentionally experimental, we create environments where innovative and transformational teaching and learning can occur. Experimentation in intentional learning spaces, however, requires more than a novel space appointed with the latest instructional technologies; it requires a mindset and acknowledgment that teaching innovations can be messy and can fail. It requires instructional design and faculty development support; it requires scholarly behaviors such as research and reflective 
practice (Borrego \& Henderson, 2014). Experimental spaces, coupled with a far-reaching model of support and a culture and process of research to practice can lead to new understandings, best practices, and new classroom designs. The impact of this framework that we have witnessed in the Bluebox raises a compelling question: Should not most classrooms be experimental spaces to support pedagogical agility?

We acknowledge, however, there are challenges. A perennial issue for our institution, and most others we have encountered, is that of scale. When more flexible and experimental spaces come online, how do we scale our research efforts? How do we scale our faculty development? The framework we propose here inherently supports, to a great extent, our scaling efforts. For example, research does not have to occur in every space to inform efforts in many spaces. We endeavor to conduct deep research in one space and then quickly return our findings to faculty teaching in other similar spaces through our faculty development efforts. Another solution to scale, not surprisingly, is varied modes of faculty development: online, face-to-face, faculty learning communities, and more.

While our data help articulate a broad research-to-practice framework, our findings also chart a course for those of us who conduct research on learning spaces. For example, future research must continue to explore questions at the intersection of learning spaces and learning design. What are the creative ways we can bring more students into our most flexible learning spaces, even when course enrollments exceed seating capacities? How do we effectively scale faculty development to support increasingly more diverse courses in a wider range of spaces? There are questions at the intersection of learning spaces and instructional technology. What is the tipping point where simple tools (e.g., writeable surfaces) outweigh sophisticated technologies in terms of impact on learning?

We need to continue to do this work, and we must continue to document it through mixed methodological approaches. Communities of research and practice centered around flexible learning spaces need rich sources of evidence about the nature of teacher and learner experiences-about what promotes quality experiences and about what impedes them. The richness of qualitative approaches and the documentation of exploratory and explanatory processes can benefit us all.

\section{Acknowledgment}

We acknowledge and appreciate the photographic and graphic design support of our colleague Geoffrey King.

\section{References}

Beach, A. L., Sorcinelli, M. D., Austin, A. E., \& Rivard, J. K. (2016). Faculty development in the age of evidence. Sterling, VA: Stylus.

Becker, S. A., Cummins, M., Davis, A., Freeman, A., Glesinger Hall, C., \& Ananthanarayanan, V. (2017). NMC horizon report: 2017 Higher education edition. Austin, TX: The New Media Consortium. Retrieved from https://www.learntechlib.org/p/174879/

Beirne, E., \& Romanoski, M. P. (2018, July). Instructional design in higher education: Defining an evolving field. In OLC outlook: An environmental scan of the digital learning landscape. Newburyport, MA: OLC Research Center for Digital Learning \& Leadership. Retrieved from https://olcwordpress-assets.s3.amazonaws.com/uploads/2018/07/Instructional-Design-in-HigherEducation-Defining-an-Evolving-Field.pdf

Borrego, M., \& Henderson, C. (2014). Increasing the use of evidence-based teaching in STEM higher education: A comparison of eight change strategies. Journal of Engineering Education, 103, 220 252. 
Caffarella, R. S., \& Zinn, L. F. (1999). Professional development for faculty: A conceptual framework of barriers and supports. Innovative Higher Education, 23, 241-254.

Clunie, L., Morris, N. P., Joynes, V. C. T., \& Pickering, J. D. (2018). How comprehensive are research studies investigating the efficacy of technology-enhanced learning resources in anatomy education? A systematic review. Anatomical Sciences Education, 11, 303-319.

Diaz, V., Garrett, E. K., Moore, J., \& Schwartz, C. (2009, March 28). Faculty development for the 21 st century [Blog post]. Retrieved from https://er.educause.edu/articles/2009/5/facultydevelopment-for-the-21st-century

Graetz, K. (2006). The psychology of learning environments. In D. G. Oblinger (Ed.), Learning spaces [EDUCAUSE $\quad$ E-book] (Chapter 6). Retrieved from https://www.educause.edu/ir/library/pdf/PUB7102f.pdf

Haras, C. (2018, January 17). Faculty development as an authentic professional practice [Blog post]. Retrieved from https://www.higheredtoday.org/2018/01/17/faculty-developmentauthentic-professional-practice/

Hartley, J. (2004). Case study research. Essential Guide to Qualitative Methods in Organizational Research, 1, 323-333.

Henderson, C., \& Dancy, M. H. (2008). Physics faculty and educational researchers: Divergent expectations as barriers to the diffusion of innovations. American Journal of Physics, 76, 79-91.

Intentional Futures. (2016, April). Instructional design in higher education: A report on the role, workflow, and experience of instructional designers [Online report]. Retrieved from https://intentionalfutures.com/wp-content/uploads/2017/08/Instructional-Design-inHigher-Education-Report.pdf

IU creates Mosaic initiative to support active learning environments: The Mosaic Active Learning Initiative enhances learning with portable whiteboards, movable furniture, and more (2015, October 13). Indiana University IT News and Events. Retrieved from https://itnews.iu.edu/articles/2015/iu-creates-mosaic-initiative-to-support-active-learningenvironments.php

Ramsay, Guo, X., \& Pursel, B. K. (2017). Leveraging faculty reflective practice to understand active learning spaces: Flashbacks and re-captures. Journal of Learning Spaces, 6, 42-53. Retrieved from http://libjournal.uncg.edu/jls/article/view/1526/1162

Robert, J.R, \& Ozkan Bekiroglu, S. (2019). Using multimodal data to construct a narrative of student engagement in an "Active Learning Classroom. Manuscript in preparation.

Rogers, D. L. (2000). A paradigm shift: Technology integration for higher education in the new millennium. AACE Journal, 1, 19-33.

Ross, S. M., Morrison, G. R., \& Lowther, D. L. (2010). Educational technology research past and present: Rigor and relevance to impact school learning. Contemporary Educational Technology, 1, $17-35$.

Van Horne, S., Murniati, J., Gaffney, J. D. H., \& Jesse, M. (2012). Promoting active learning in technology-infused TILE classrooms at the University of Iowa. Journal of Learning Spaces, 1(2). Retrieved from https://libjournal.uncg.edu/jls/article/view/344

Yoon, K. S., Duncan, T., Lee, S. W.-Y., Scarloss, B., \& Shapley, K. (2007). Reviewing the evidence on how teacher professional development affects student achievement (Issues \& Answers Report, REL 2007-No. 033). Washington, DC: U.S. Department of Education, Institute of Education Sciences, National Center for Education Evaluation and Regional Assistance, Regional Educational Laboratory Southwest. Retrieved from http://ies.ed.gov/ncee/edlabs 